\title{
ANÁLISE DAS LEGISLAÇÕES BRASILEIRA E ARGENTINA QUE ABORDAM A TÉCNICA INVESTIGATIVA DENOMINADA AGENTE INFILTRADO/ENCUBIERTO
}

Ionéia de Sousa Marques

Especializanda em Justiça Criminal e Sistemas Jurídicos pela Escola Superior do Ministério Público. Bacharela em Direito (FA7).

ioneiamarques@yahoo.com.br

Luiz Claudio Araújo Coelho

Mestre em Educação (UECE). Especialista em Gestão Estratégica de Políticas de Segurança Pública (UECE). Bacharel em Direito (FA7).

bleve@bol.com.br.

Sumário: Introdução. 1. Conceito de crime organizado. 2. Agente infiltrado: conceito e utilização da técnica. Considerações finais. Referências.

Resumo: É preciso conhecer os mecanismos legais para prevenção e repressão da criminalidade organizada, pois o sucesso das investidas públicas passa obrigatoriamente pelo acionamento correto e tempestivo desses mecanismos. O presente trabalho se debruça sobre os elementos investigativos lançados pelas Leis n. ${ }^{\text {ss }} 9.034 / 95$ e $10.217 / 01$, no caso brasileiro, e as Leis n. ${ }^{\text {os }} 24.424$ e 23.737, no caso Argentino, que tratam especificamente da técnica investigativa contra o crime organizado denominada agente infiltrado/encubierto. Para tanto, desenvolveu-se uma pesquisa de cunho qualitativo, mobilizando elementos da pesquisa bibliográfica e documental. Os meios operacionais abordados pela Lei n. ${ }^{\circ}$ 9.034/95 são todas as ferramentas disponíveis de que o Estado poderá se utilizar durante a investigação extrajudicial, incluindo a técnica do agente infiltrado ou agente encubierto, para obtenção de provas, observando a ampla defesa e o contraditório. Há certa aproximação entre a legislação brasileira e a legislação Argentina sobre esta técnica. Entretanto, o ordenamento jurídico argentino apresenta duas iniciativas legislativas que protegem o agente encubierto, afastando a punibilidade do agente infiltrado pelos crimes necessários praticados durante a infiltração e a punição de agentes públicos que denunciam a condição de encubierto de um agente, ainda que de modo culposo.

Palavras-chave: Crime organizado. Mecanismos investigativos. Agente infiltrado.

Brasil. Argentina.

\section{INTRODUÇÃO}

A criminalidade organizada é tema que se mantém permanente na mídia atualmente. Contudo, suas primeiras manifestações remontam a períodos bem afastados na história. As primeiras manifestações do crime organizado podem ser reconhecidas nas atuações de quadrilhas em tempos remotos. Exemplo rudimentar deste fato é o cangaço manifestado no sertão nordestino no início do século XX. 
Devido ao aumento das atividades das organizações criminosas, os legisladores brasileiros e argentinos tentam dotar seus ordenamentos jurídicos de mecanismos eficazes de combate a esse tipo de conduta delituosa. A despeito dessa intenção, as investidas do poder público mostram-se tímidas e inócuas para enfrentar o crime organizado. É preciso conhecer os mecanismos legais para prevenção e repressão da criminalidade organizada, pois o sucesso das investidas públicas passa obrigatoriamente pelo acionamento correto e tempestivo desses mecanismos.

Desse modo, o presente trabalho se debruça sobre os elementos investigativos lançados pelas Leis n. ${ }^{\text {os }}$ 9.034/95 e 10.217/01, no caso brasileiro, e as Leis n. ${ }^{\text {os }} 24.424$ e 23.737, no caso Argentino, que tratam especificamente da técnica investigativa contra o crime organizado denominada agente infiltrado (agente encubierto). Para tanto, desenvolveu-se uma pesquisa de cunho qualitativo, mobilizando elementos da pesquisa bibliográfica e documental, sendo as aludidas legislações os documentos básicos da pesquisa.

Inicia-se o artigo com uma discussão acerca da definição legal desse instituto, evidenciando as debilidades vigentes. Por fim, são apresentados os requisitos para acionamento do mecanismo investigativo denominado agente infiltrado ou agente encubierto para a prevenção e a repressão do crime organizado.

\section{CONCEITO DE CRIME ORgANIZAdo}

O conceito de crime organizado não foi estabelecido pelo legislador brasileiro ao criar as Leis n. ${ }^{\text {os }} 9.034 / 95$ e 10.217/01, normas que tratam desta modalidade delituosa. A Lei n. ${ }^{\circ}$ 9.034/95 foi concebida com o intuito de dar regulamentação legal ao enfrentamento do crime organizado. Entretanto, em seu bojo só regula apenas os meios de prova e os procedimentos investigatórios que tratam dos crimes de quadrilha ou bando, omitindo o termo organizações criminosas. Esse fato constitui uma lacuna severa no ordenamento jurídico no que tange ao crime organizado, dificultando a ação do Estado no enfretamento de tal modalidade criminosa. Este fato trouxe dúvidas acerca das ações a serem empregadas pelo poder público. Afinal, a Lei se refere às quadrilhas ou bandos, como disciplina o artigo primeiro, ou se refere às organizações criminosas?

Deste dilema surgem duas correntes antagônicas. A primeira defende que organização criminosa é sinônimo de quadrilha ou de bando, delito que a legislação em estudo regulamenta. A segunda corrente, argumenta que organização criminosa é mais do que quadrilha ou bando e que ela se constitui de algum outro ou outros requisitos que a lei não determinou de modo claro.

Por falta de uma definição legal, as discussões doutrinárias do Direito se ocuparam da tarefa de conceituar crime organizado. Assim, algumas definições foram elaboradas e gozam de certo acolhimento pelos operadores do direito. Vislumbra-se dentre estas definições a denúncia de Zaffaroni (2007, p. 1-2) sobre a aproximação do conceito de crime organizado à criminalidade de mercado:

\footnotetext{
El crimen organizado es un concepto de origen periodístico, que nunca alcanzó una satisfactoria definición criminológica, pero que se trasladó a la legislación penal y procesal penal para aumentar el ejercicio del poder punitivo respecto de un conjunto de delitos no bien delimitado, lo que pretende configurar un derecho penal diferenciado y con menores garantías para un ámbito delictivo sin delimitación. Su idea más aproximada está dada por la criminalidad de mercado, abarcando desde todos los tráficos prohibidos hasta el juego, la prostitución, las diferentes formas de comercio sexual, la falsificación de moneda y los secuestros extorsivos. No faltan leyes que incluyen al terrorismo en su concepto legal.
} 
Juarez Cirino dos Santos (2003, p. 215) nos traz em seus ensinamentos que "na verdade, existem dois discursos sobre o crime organizado estruturado nos pólos americano e europeu do sistema capitalista globalizado: o discurso americano sobre organized crime, definido como conspiração nacional de etnias estrangeiras, e o discurso italiano sobre crimine organizato, que tem por objeto o estudo original da Máfia Siciliana”.

Mingardi (1998) divide o crime organizado em tradicional (ou territorial) e empresarial. O empresarial teria como "característica mais marcante transpor para o crime métodos empresariais, ao mesmo tempo em que deixam de lado qualquer resquício de conceitos como honra, lealdade, obrigação, etc" (MINGARDI, 1998, p. 88) e trata como crime organizado tradicional:

Grupo de pessoas voltadas para atividades ilícitas e clandestinas que possui uma hierarquia própria e capaz de planejamento empresarial, que compreende a divisão do trabalho e o planejamento de lucros. Suas atividades se baseiam no uso da violência e da intimidação, tendo como fonte de lucros a venda de mercadorias ou serviços ilícitos, no que é protegido por setores do Estado. Tem como características distintas de qualquer outro grupo criminoso um sistema de clientela, a imposição da lei do silêncio aos membros ou pessoas próximas e o controle pela força de determinada porção de território (MINGARDI, 1998, p. 82).

O legislador pátrio com o intuito de sanar a lacuna deixada pela Lei n. ${ }^{\circ}$ 9.034/95, artigo $1^{\circ}$, cria a Lei n. ${ }^{\circ} 10.217 / 2001$. Entretanto, o impasse permaneceu, pois embora o objetivo da lei tenha sido ampliado, alcançando as quadrilhas ou bandos dispostos no artigo 288 do Código Penal, associações criminosas de qualquer tipo (artigo 14 da Lei n. ${ }^{\circ}$ 6368/76) e as organizações criminosas de qualquer tipo, continuou sem dar definição legal para organização criminosa.

Diante de todo este debate a respeito do conceito de crime organizado, a Convenção de Palermo, que foi ratificada pelo Decreto Lei n. ${ }^{\circ} 231$ trouxe a solução do problema. O Superior Tribunal de Justiça adotou este posicionamento, ou seja, reconheceu a conceituação de organização criminosa trazida pela convenção.

Neste sentido, leciona o professor Capez (2006, p. 92) que "toda a discussão acima exposta tende, no entanto, a ficar superada. A Convenção das Nações Unidas contra o Crime Organizado Transnacional, realizada em Palermo, na Itália, em 15 de dezembro de 2000, definiu, em seu art. $2^{\circ}$, o conceito de organização criminosa.

Para a Convenção de Palermo, organização criminosa é grupo organizado com três ou mais pessoas, existindo há algum tempo e atuando concertadamente com o fim de cometer infrações graves, com a intenção de obter benefício econômico ou moral. Este é o dispositivo legal adotado pelo Brasil na atualidade.

O artículo 210 do Codigo Penal de La Nación Argentina estabelece que o fato tipificado como associação ilícita ocorre quando "el que tomare parte en una asociación o banda de tres o más personas destinada a cometer delitos por el solo hecho de ser miembro de la asociación". Nesse sentido, D’Alessio (2004, p. 681) esclarece as similitudes dos dois injustos penais, declinando as características do tipo argentino que muito se assemelha ao injusto brasileiro:

Lo que importa es que exista un pacto de voluntades comunes en relación con una organización cuya actividad principal sea la de perpetrar hechos ilícitos en forma indeterminada, aunque se ha sostenido que los delitos deben estar determinados y deberán especificarse al momento de efectivizar la acusación. Alguna doctrina y jurisprudencia ha señalado que la exigencia de que los delitos sean indeterminados no se refiere a que los miembros de la asociación no sepan qué delitos ésta va a cometer, sino a que tengan en sus miras una pluralidad de planes delictivos que no se agote en una conducta delictiva determinada con la concreción de uno o varios hechos. Se ha mencionado también que 
la indeterminación radica en el modo, tiempo y lugar de llevarlos a cabo. La asociación ilícita requiere pluralidad de planes delictivos y no meramente pluralidad de delitos, que pueden ser independientes entre sí aunque similares en su finalidad, de modo tal que pueda presumirse la confabulación exigida por el arto 210 del Cód. Penal.

O artículo 210 bis do mesmo diploma legal prescrevem as características de possíveis elementos que podem compor uma ação delituosa. Com a conjugação de dois ou mais elementos descritos, o legislador argentino previu a ocorrência da associação ilícita qualificada, sendo penalizada com maior severidade:

Art. 210 bis. - Se impondrá reclusión o prisión de cinco a veinte años al que tomare parte, cooperare o ayudare a la formación o al mantenimiento de una asociación ilícita destinada a cometer delitos cuando la acción contribuya a poner en peligro la vigencia de la Constitución Nacional, siempre que ella reúna por lo menos dos de las siguientes características:

a) Estar integrada por diez o más individuos;

b) Poseer una organización militar o de tipo militar;

c) Tener estructura celular;

d) Disponer de armas de guerra o explosivos de gran poder ofensivo;

e) Operar en más de una de las jurisdicciones políticas del país;

f) Estar compuesta por uno o más oficiales o suboficiales de las fuerzas armadas o de seguridad;

g) Tener notorias conexiones con otras organizaciones similares existentes en el país o en el exterior;

h) Recibir algún apoyo, ayuda o dirección de funcionarios públicos.

Assim, o injusto de agremiação criminosa na Argentina ocorre com a ocorrência de duas ou mais características tipificadas no artículo 210 bis, caracterizando o agravamento da associação. Nesse sentido, entende-se que o ordenamento jurídico argentino alberga com maior amplitude as ações de delitos organizados, imputando uma responsabilidade penal mais severa aos agentes que o ordenamento brasileiro.

\section{Agente INFILTRADO: CONCEITO E UTILIZAÇÃO DESTA TÉCNICA}

O Brasil tem buscado por meio do seu ordenamento jurídico criar mecanismos que possibilitem tornar mas eficiente o aparelho estatal para o enfrentamento do crime organizado. Entre estes mecanismos que a lei disponibiliza, está a figura do agente infiltrado. Esta técnica permitirá, em determinados casos que o Estado aplique, como determina a norma jurídica, este recurso tanto no que se refere ao crime organizado dentro do País, mas também no enfrentamento ao crime organizado transnacional.

Os elementos caracterizados do crime organizado podem ser definidos por alguns elementos de sua constituição, tais como a estrutura hierarquizada, atividades ilícitas para obtenção de ganhos financeiros, caráter estruturado e permanente para a prática de ilícitos, bem como o emprego da violência e coação. Nesse sentido, Ochoa (2006, p. 56) indica:

En un sentido estricto, desde una perspectiva funcionalista, la delincuencia organizada es la que se realiza a través de un grupo o asociación criminal revestido de las siguientes características: carácter estructurado, permanente, auto renovable, jerarquizado ,destinado a lucrarse con bienes y servicios ilegales ; empleando la disciplina y la coacción en relación con sus miembros y toda clase de medios frente a terceros, con el propósito de alcanzar sus objetivos. 
Assim, a Lei n. ${ }^{\circ}$ 9034/95 vem regular as ações que buscam combater tais atividades delituosas. No inciso $\mathrm{V}$ do artigo $2 .^{\circ}$ aborda a previsão da técnica da infiltração de agente de polícia ou de inteligência, como um dos procedimentos de investigação e colheita de provas. Este procedimento de investigação ocorre por meio de órgãos especializados e competentes, mediante autorização judicial.

O mecanismo da infiltração de agente de polícia ou de inteligência, que dispõe a Lei n. ${ }^{\circ}$ 9034/95, também encontra previsão legal na Convenção das Nações Unidas como mecanismo de combate ao crime organizado transnacional. O Brasil, ao recepcionar a Convenção das Nações Unidas, por força do Decreto n. ${ }^{\circ}$ 5015/2004, assume a obrigação de utilizar todos os mecanismos disponíveis em lei, entre eles a infiltração de agentes de polícia ou de inteligência.

Neste sentido leciona Dezem (2010, p. 157) que "a técnica da infiltração de agentes de polícia ou de inteligência constitui-se em obrigação assumida pelo Brasil internacionalmente por meio do Decreto n. 5.015/2004, que Promulga a Convenção das Nações Unidas contra o Crime Organizado Transnacional".

O artigo. 20,1, da aludida Convenção traz a regulamentação das técnicas especiais de investigação, que indica dentre outros mecanismos de investigação permitidos pela lei nacional, indica a infiltração do agente como modalidade de investigação.

Se os princípios fundamentais do seu ordenamento jurídico nacional o permitirem, cada
Estado-Parte, tendo em conta as suas possibilidades e em conformidade com as condições
prescritas no seu direito interno, adotará as medidas necessárias para permitir o recurso
apropriado a entregas vigiadas e, quando o considere adequado, o recurso a outras técnicas
especiais de investigação, como a vigilância eletrônica ou outras formas de vigilância e
as operações de infiltração, por parte das autoridades competentes no seu território, a fim
de combater eficazmente a criminalidade organizada.

O agente infiltrado deve ser um servidor público, não podendo ser um informante qualquer, que não esteja subordinado aos ditames do exercício público. Deste modo, não cabe a um particular a figura do agente infiltrado. Esta tarefa de agente infiltrado será apenas de um funcionário da polícia que terá sua identidade, preservada e falseada, enquanto estiver na operação de agente infiltrado. Este funcionário deverá estar exercendo suas atividades, junto ao seu órgão, pois nesta operação o agente público está amparado pelo Estado, visto que este é um representante do mesmo.

\section{Consoante este entendimento, lecionam Conserino, Vasconcelos e Magno} (2011, p. 82):

\footnotetext{
A infiltração de particular. Não há previsão legal para isso. A infiltração de "gansos" ou "informantes", civis que trabalham esporadicamente para a policia, sem qualquer hierarquia funcional, também é vedada e quem assim proceder responderá pelas consequências de seu ato, certo, ainda, que a prova amealhada nessas circunstâncias não será considerada válida e lícita.
}

Barbosa (2008) atribuía à técnica do agente infiltrado uma medida de eficácia para combater o crime organizado. O agente infiltrado tem sua identidade preservada, para poder, dentro da organização criminosa, descobrir delitos, verificar a ideologia ou ação da organização e seus chefes.

El agente encubierto ES uma de lãs medidas de mayor eficácia em La lucha contra La criminalidad organizada, es um instrumento caracterizado por La infiltración de miembros de lãs fuerzas de seguridad en lãs organizaciones criminales, quienes ocultan su autentica 
identidad con el propósito de detectar y perseguir delitos. Del mismo modo, este tipo de medidas buscan la verificación de ideólogos y dirigentes de tales organizaciones (BARBOSA, 2008, p.90).

Pacheco (2007, p. 109) apresenta como conceito de agente infiltrado "o funcionário da polícia que, falseando sua identidade, penetra no âmago da organização criminosa para obter informações e, dessa forma desmantelá-la". Verificam-se aqui os requisitos formais, ao menos em primeiro plano, já declinados acima, para a caracterização subjetiva do agente a ser infiltrado na organização criminosa.

$\mathrm{O}$ agente infiltrado tem por objetivo buscar informações e descobrir as atividades ilícitas que determinada organização criminosa exerce, com a finalidade de serem utilizadas como elemento probatório. A Convenção das Nações Unidas delega esta atividade ao infiltrado, salientando a observância no que se refere ao respeito às garantias e princípios fundamentais de cada Estado. Prevê ainda que as técnicas declinadas pela Convenção que ora tratamos, possui o condão de combater a corrupção que se infiltra no seio da máquina estatal, servindo assim as aludidas técnicas como meio de prova contra esta pratica.

\footnotetext{
La actividad del agente encubierto está dirigida a tareas de información y verificación de las actividades criminales, para de tal forma descubrir los delitos y garantizar los elementos probatorios. Al respecto, la Convención de Naciones Unidas contra el criminen organizado de 2000, y la Convención contra la Corrupción de 2003, prevén que en atención con los principios y garantías fundamentales previstas en los ordenamientos de los Estados, el reconocimiento de las técnicas especiales de investigación como las operaciones encubierto. La Convención contra la corrupción señala que los Estados tomaran las medidas necesarias para posibilitar la admisión de las pruebas emanadas de dicha técnica (BARBOSA, 2008, p. 90).
}

Nesse sentido, buscar-se-á caracterizar de modo completo os requisitos necessários à eficácia desta técnica investigativa no tópico seguinte, uma vez que deve-se respeitar as garantias previstas na Constituição Federal, sob pena de se incorrer na formação de provas ilícitas, sem nenhum valor para o processo.

\subsection{Requisitos necessários para a eficácia do agente de infiltração}

Para que o instituto do agente infiltrado possa encontrar legitimidade, é necessário que se observe a lei que disciplina este instrumento. Sendo assim, a norma determina que haja circunstanciada autorização judicial. O juiz deverá indicar o que o levou a deferir a favor da necessidade da utilização da infiltração. Esta motivação está presente no principio da motivação das decisões, prevista no Código de Processo Penal brasileiro e argentino, em que determina que todos os atos praticados pelo magistrado têm que ser por ele, justificados e fundamentados.

Portanto, as circunstâncias em que se operará o instrumento da infiltração, qual será o grupo atingido pela infiltração, qual será o tempo de operação, e em que circunscrição territorial ira abranger a operação do agente infiltrado, tudo deve ser previamente estabelecido pela autoridade competente.

No mesmo diapasão, Guilherme Madeira Dezem leciona:

Em verdade, ao determinar que a autorização seja circunstanciada, deve o magistrado indicar os motivos pelos quais derefe a infiltração policial. Da mesma forma, deve indicar as circunstancias em que se desenvolverá tal infiltração, vale dizer: em qual grupo criminoso 
será feita a infiltração, por quanto tempo perdurará a infiltração, qual a extensão territorial da atividade desenvolvida pelo agente infiltrado, entre outras medidas (DEZEM, 2010, p. 158).

No mesmo sentido, Conserino, Vasconcelos e Magno trazem à baila os requisitos que necessitam estar presentes ao se determinar uma infiltração policial ou de agentes de inteligência. A relação declinada pelo autor em questão indica todos os elementos caracterizadores da subjetividade permitida pela lei à mobilização do agente infiltrado:

a) Prévia autorização judicial circunstanciada e detalhada impondo, pelo menos, limite de duração razoável da infiltração, com algumas diretrizes de formalidades a serem seguidas. Note que são diretrizes e não determinação, até porque é o agente infiltrado que tem a técnica para realizar a infiltração, cabendo ao Poder Judiciário a análise jurídica sobre o tema.

b) Os atos típicos da organização criminosa hão de estar em curso para que sobrevenha a infiltração, sob pena de, não estando em curso, o agente infiltrado passe a funcionar como instigador ou induzidor do crime, produzindo, pois, a figura do flagrante preparado e eivando de nulidade a prova colhida. Aliás, também passaria a funcionar como integrante da organização criminosa na realização de seus atos típicos.

c) Demonstração da necessidade da infiltração, ou seja, demonstração de que a prova obtida com a infiltração não seria obtida com nenhuma outra medida.

d) Observância ao princípio da proporcionalidade.

e) Sigilo absoluto, objetivando, primacialmente, assegurar o sucesso da diligência e a segurança do infiltrado (CONSERINO, 2011, p. 82)

Os ritos procedimentais da infiltração policial ou por agente de inteligência, foram regulamentados por analogia, pela Lei n. ${ }^{\circ}$ 9.296/966 que regula a interceptação telefônica, uma vez que não havia um procedimento próprio para o instituto da infiltração. Nesse momento, a técnica em estudo dispunha de suporte jurídico superficial, sem contar que sequer dispunha acerca da proteção à integridade ou da responsabilidade penal do agente.

O requerimento da infiltração poderá ser realizado ex officio de uma autoridade policial, de Promotor de Justiça ou Procurador da República. No caso do pedido se manifestar por uma autoridade policial, o Ministério Público deverá ser comunicado. O poder judiciário deverá a cada quinze dias, tomar ciência de como está procedendo infiltração e como a organização criminosa está atuando.

\subsection{Responsabilidade penal do agente infiltrado}

A Lei n. ${ }^{\circ}$ 9034/95 não traz qualquer previsão a cerca da atuação do agente infiltrado, ficando com a doutrina a responsabilidade por discorrer sobre este entendimento. Neste sentido, surgem duas correntes contrárias: uma defende que o agente deverá ser responsabilizado por seus atos ilícitos cometidos durante a infiltração, por não haver previsão de excludente de ilicitude destes atos ilícitos; outra, pugna pela totalmente exclusão de sanção aos ilícitos produzidos pelo agente infiltrado.

Segundo Rocha (2002), Luiz Flávio Gomes mostra-se decididamente favorável à responsabilização do agente infiltrado pelas condutas delituosas praticadas, uma vez que a legislação nacional não contempla nenhuma excludente de criminalidade. Por sua vez, Pacheco (2007), entende que Issac Sabbá Guimarâes trilha por mesmo entendimento, sem apresentar nenhum conflito.

Posicionamento diverso é apresentado por Rocha (2002), ao afirmar que as correntes divergentes podem ser manifestadas no ordenamento brasileiro. Para o autor, a responsabilidade do agente poderá ser de escusa absolutória, segundo a qual o agente comete o crime mas a penalização da conduta não ocorre por razões de política criminal. Esse posicionamento não é 
aproveitado pelos copartícipes da conduta delitiva que pertencem a organização criminosa, tendo por fundamento o caráter subjetivo da exclusão da sanção. Há outra linha de pensamento do autor na qual beneficia aos copartícipes, retirando inclusive a pena ao se considerar como exclusão da ilicitude ou culpabilidade, o caráter do estrito cumprimento do dever legal, ou ainda do exercício regular de direito, ou da obediência à ordem hierárquica não manifestamente ilegal.

Capez (2006) esclarece que o agente é sempre responsável pelos crimes que vier a praticar, por não haver permissivo legal para ampará-lo. Entretanto, o autor defende que a conduta do agente poderá ser considerada atípica quando realizada em consonância com o princípio da proporcionalidade e da adequação social; neste sentido, exclui a materialidade do crime. Alegando o estado de necessidade a sanção poderá ser afastada, ao se pesar que o bem jurídico lesado, e o benefício de desmantelamento de uma organização criminosa torna-se evidente, que o valor do bem jurídico lesionado torna-se menor.

\subsection{A infiltração de agentes no ordenamento jurídico argentino}

A Lei n. ${ }^{\circ} 24.424$, de janeiro de 1995 , que veio alterar a Lei $n .^{\circ} 23.737$, que regulamenta a técnica do agente infiltrado no ordenamento jurídico argentino, incluiu novos dispositivos. De acordo com o artigo $6^{\circ}$ (que insere o artigo 31 bis à Lei n. ${ }^{\circ}$ 23.737), só poderá utilizar a técnica do agente infiltrado no curso de uma investigação e com o objetivo de comprovar o cometimento de crimes previstos no texto desta lei em estudo, ou os delitos previstos no artigo 866 do Código Aduaneiro.

A lei Argentina somente permite o procedimento do agente infiltrado quando já há uma investigação em curso, não podendo utilizar-se deste recurso para se iniciar um procedimento penal.

Como no Brasil, a infiltração na argentina deve ser autorizada previamente por um magistrado, e, quando infiltrado, o agente terá que imediatamente levar as informações da sua investigação ao juízo que o autorizou, nos termos do artigo $6^{\circ}$ da Lei n. ${ }^{\circ} 24.424$ (artigo 31 bis da Lei n. ${ }^{\circ}$ 23.737).

O ordenamento jurídico da Argentina se aproxima da legislação brasileira, ao não permitir que o infiltrado seja um particular, ou seja, um sujeito estranho ao serviço público, que não seja um indivíduo ocupante dos quadros das forças de segurança pública daquele País. De acordo com a Lei n. ${ }^{\circ}$ 24.424, o agente infiltrado deve ser um "agente de las fuezas de seguridad em actividad". Desta forma, exclui-se a possibilidade de o agente infiltrado ser das forças policiais da Polícia Federal argentina e polícias provinciais.

Diferente do diploma brasileiro, que é omisso no que concerne aos delitos cometidos por agentes infiltrados no curso da operação, a norma argentina optou por criar uma hipótese de escusa absolutória, para isentar o agente infiltrado de responsabilidade sobre os delitos que venha cometer durante o tempo da infiltração. A lei Argentina prevê que não serão punidos os delitos necessários para que se desenvolva a infiltração, desde que sejam consequências necessárias da atuação do agente, e que o agente tenha sido compelido a cometê-los, não tendo lhe restado outra opção. Observa-se que a lei não oferece impunidade absoluta, mas exclui da escusa absolutória os delitos que coloque em risco a vida ou a integridade física de outras pessoas, ou ainda que cause grave sofrimento físico ou moral de terceiros, conforme o artigo $7^{\circ}$ da Lei n..$^{\circ} 24.424$, que incorpora o artigo 31,3 à lei n. ${ }^{\circ} 23.737$.

A Lei n. ${ }^{\circ} 24.424$ determina que, nos casos de se utilizar as informações obtidas através da infiltração em juízo, estas informações serão consideradas como elemento probatório e o agente será ouvido como testemunha. Diante desta possibilidade a lei traz uma série de mecanismos de proteção para o agente.

Com o fito de trazer maior segurança ao agente infiltrado, a lei Argentina prescreve em seu artigo 10 que a criminalização da conduta do servidor público que promover a revelação 
da operação para terceiros, seja por imprudência, negligência ou inobservância de seus atributos funcionais. Este ponto se distancia do ordenamento jurídico brasileiro, pois este não contempla nem uma previsão legal neste sentido.

\section{CONSIDERAÇões FINAIS}

Diante dos delineamentos apresentados, comprova-se que o Estado Brasileiro dispõe de mecanismos jurídicos e de investigação diferenciados para realizar o enfrentamento do crime organizado, bem como dispõe da técnica de infiltração de policiais ou de agentes de Inteligência. Há certa aproximação entre a legislação brasileira e a legislação Argentina sobre esta técnica. Entretanto, o ordenamento jurídico argentino apresenta duas iniciativas legislativas que protegem o agente encubierto, afastando a punibilidade do agente infiltrado pelos crimes necessários praticados durante a infiltração e a punição de agentes públicos que denunciam a condição de encubierto de um agente, ainda que de modo culposo.

É preciso empreender esforços concentrados para se desarticular o crime organizado, que tem feito os cidadãos brasileiro e argentino reféns do medo. Vive-se nas grandes cidades em casas transformadas em trincheiras, abrigando os cidadãos e familiares, enquanto a criminalidade organizada suga os recursos do Estado, aumentando ainda mais o grupo de excluídos dos benefícios coletivos conquistados pela sociedade.

\section{REFERÊNCIAS}

BARBOSA, Paula Andrea Ramírez. Nuevas tendencias político-criminales em La lucha contra La criminalidad organizada. El modelo de Colombia em este âmbito. In: CALLEGARI, André Luís; MELIÁ, Manuel Câncio; BARBOSA, Paula Andrea Ramírez. Crime organizado: tipicidade, política criminal, investigação e processo: Brasil, Espanha e Colômbia. Porto Alegre: Livraria do Advogado, 2008.

CAPEZ, Fernando. Legislação Penal Especial: juizados especiais criminais: interceptação telefônica: crime organizado: tóxicos. 5. ed. São Paulo: Damásio de Jesus, 2006.

CAPEZ, Fernando. Curso de Direito Penal, v. 4: legislação penal especial. São Paulo: Saraiva, 2006. CONSERINO, Cassio Roberto; VASCONCELOS, Clever Rodolfo Carvalho; MAGNO, Levy Emanuel (org.). Crime organizado e institutos correlatos. (Série legislação penal especial). São Paulo: Atlas, 2001.

D’ALESSIO, Andres José. Código Penal: comentado y anotado: parte especial (arts. 79 a 306). Tomo II. Buenos Aires: La Ley, 2004.

GOMES, Luiz Flávio; CERVINI, Raúl. Crime organizado: enfoques criminológico, jurídico (Lei 9034/95) e político criminal. 2. ed. rev. atual. e ampliada. São Paulo: Revista dos Tribunais, 1997.

GOMES, Luiz Flavio; CERVINI, Raul. Crime organizado: enfoques criminológico, jurídicocriminal. 2. ed. São Paulo: Revista dos Tribunais,1997a.

LAVORENTI, Wilson; SILVA, José Geraldo da. Crime organizado na atualidade. Campinas: Bookseller, 2000.

MARCOS, Fernando Bermejo. La globalización del crimen organizado. Eguzkilore - Cuaderno del Instituto Vasco de Criminología, n. 23, San Sebastián, Diciembre 2009: p. 99 - 115. Disponível em: $<$ http://www.ivac.ehu.es/p278-content/es/contenidos/boletin_revista/eguzkilore_23_homenaje_ab/ es_eguzki23/adjuntos/10-Bermejo.indd.pdf>.Acesso em: 5.fev.2012. 
MAIEROVITCH, Walter Franganiello. As associações mafiosas. RCEJ. Brasília, v. 1, n. 2, p. 101-107, mai./ago.1997.

MINGARDI, Guaracy. O Estado e o crime organizado. São Paulo: IBCCrim, 1998.

OCHOA, Ramón De La Cruz. Crimen Organizado: delitos más frequentes - aspectos criminologicos e penales. Granada: [s/1], 2006.

PACHECO, Rafael. Crime organizado: medidas de controle e infiltração policial. Curitiba: Juruá, 2007.

RINALDI, Stanislao. Criminalidade organizada de tipo mafioso e poder político na Itália. Revista Brasileira de Ciências Criminais, São Paulo, n. 22, p. 11-25, abr./jun. 1998.

ROCHA, Luiz Otávio de Oliveira. Agente Infiltrado: inovação da Lei n 10.217/2001. Revista Ibero-Americana de Ciências Penais, Porto Alegre, ano 3, nº 5, p. 49-68, jan./abr.2002.

SANTOS, Juarez Cirino dos. Crime organizado. Revista Brasileira de Ciências Criminais, São Paulo, n. 42, p. 214-224, jan./mar. 2003

ZAFFARONI, Eugenio Raúl. Globalización y crimen organizado. Revista Pensamiento Penal, ed. 117, Rio Negro, 2007. Disponível em: <http://www.pensamientopenal.com.ar/01022011/ doctrina01.pdf>. Acesso em: 5.fev.2012.

\title{
ANALYSIS OF BRAZILIAN AND ARGENTINEAN LAWS REGARDING THE INVESTIGATIVE TECHNIQUE NAMED INFILTRATED AGENT/ENCUBIERTO
}

\begin{abstract}
This paper focuses on the elements of investigation launched by the Laws 9.034/95 and 10.217/01, in Brazil, and the Laws 24,424/95 and 23,737/89, in Argentina, which deal specifically with the investigative technique against organized crime called infiltrated agent. There is some similarity between the laws of Brazil and Argentina about this technique. However, the Argentine legal system has two legislative initiatives that protect the infiltrated agent, eliminating the punishment of crimes practiced by the infiltrated agent during infiltration and punishment of officials who denounce the condition of an infiltrated agent, even if guilty.

Keywords: Organized Crime. Investigative mechanisms. Infiltrated agent. Brazil. Argentina.
\end{abstract}

